\title{
ANTIFUNGAL EFFECTS OF MICROMERIA MYRTIFOLIA BOISS. \& HOHEN. IN BOISS. AND PRANGOS UECHTRITZII BOISS. HAWSSKN DECOCTIONS
}

\author{
M. ÖZCAN \\ Department of Food Engineering, Faculty of Agriculture, Selçuk University, 42031 Konya, Turkey \\ (Received: 8 February 1999; accepted: 17 May 1999) \\ Antifungal effect of Micromeria myrtifolia Boiss. \& Hohen. in Boiss. and Prangos \\ uechtritzii Boiss. Hawsskn decoctions was tested against Alternaria alternata, Aspergillus niger, \\ Aspergillus parasiticus, Botrytis cinerea, Fusarium oxysporum f.sp. melonis and Penicillium \\ digitatum. Of the 2 substances tested $P r$. uechtritzii, being present at 75 to $80 \%$ concentration in \\ potato dextrose agar, partly inhibited growth of A. alternata, B. cinerea and P. digitatum. Pr. \\ uechtritzii had higher antifungal effect than M. myrtifolia on mycelial growth during incubation. \\ M. myrtifolia partly affected mycelial growth of A. alternata and A. niger at the beginning of \\ incubation. But the mycelial growth of $F$. oxysporum was not inhibited by $M$. myrtifolia \\ concentrations during incubation. Also, Pr. uechtritzii did not have any affect on mycelial growth \\ of $A$. niger during incubation $P$. digitatum, the most sensitive microorganism to both decoctions. \\ Higher decoction concentrations of plants used in study will be probably inhibit mycelial growth \\ of microorganisms.
}

Keywords: antifungal effect, decoction, inhibition, moulds

Micromeria myrtifolia Boiss. \& Hohen. in Boiss. and Pr. uechtritzii Boiss. Hawsskn grow as wild, and are known as taş Çayı and Çaşır in Turkey, respectively. $M$. myrtifolia is drunk as tea. But Pr. uechtritzii is used as vegetable and pickling product. Although spices are used primarily for their desirable flavour and odour, they may play other important roles in food systems. They are highly valued for their use as antimicrobial agents. Antimicrobial properties of spices and of their essential oils have been documented. The preservative action of herbs and spices has only recently received attention in the literature where studies have been reported that mycotoxinproducing moulds may be inhibited by some herbs and spices. Past investigations have indicated that the antimicrobial factor of spices resides in the essential oil/or oleoresin fraction. Aromatic plants/spices, herbs and derivatives widely used in foods were used 
as antimicrobial agents against several microorganisms under in vitro conditions. While antimicrobial activities of several spices in culture media have been reported over the years, few tests have been conducted in food systems (BEuCHAT, 1976; SHELEF et al., 1980, HITOKOTO et al., 1980; AZZOUZ \& BULLERMAN, 1982; ZAIKA et al., 1983; FARAG et al., 1989; BENJILALI et al., 1984; GRAHAM \& GRAHAM, 1987; BOYRAZ \& ÖZCAN, 1997)

There are several chemicals that can be used as antimicrobial agents. For instance, acetic acid and sulfur dioxide are widely used as food preservatives. However, these chemicals require caution in handling since they are corrosive and their vapours can irritate the eyes and respiratory tract. On the contrary, herbs and their derivatives possessing antimicrobial activity, might have beneficial effect, but cause no health problems to the handler and consumer. In this respect, various essential oils of spices were tested for their inhibitory activity towards the growth of some microorganisms.

The objective of this work was to evaluate the inhibitory potency of M. myrtifolia and $P$. uechtritzii decoctions on A. alternata, A. niger, A. parasiticus, B. cinerea, $F$. oxysporum and $P$. digitatum in vitro.

\section{Materials and methods}

\subsection{Materials}

Micromeria myrtifolia Boiss. \& Hohen. in Boiss. (Labiatae) and Prangos uechtritzii Boiss. Hawsskn (Apiaceae) used in the experiments were collected from Mersin (Gülnar) and Kayseri, respectively, in 1997. Plants were identified at the Department of Biology, Faculty of Science and Education, Selçuk University.

\subsection{Organisms}

Moulds used in this study were: A. parasiticus NRRL 2999, obtained from USDA, Agricultural Res. Service, National Center for Agricultural Utilization Res. Service, Illinous, USA; A. alternata, A. niger, B. cinerea, $F$. oxysporum and $P$. digitatum obtained from Department of Food Engineering, Faculty of Agriculture, Selçuk University. 


\subsection{Medium}

Potato dextrose agar (E. Merck, Darmstadt) was used as main medium in the experiment. Plants used in this study were boiled in water $(1: 2, \mathrm{w} / \mathrm{v})$ for one hour. After the decoctions were filtered, they were cooled and stored in refrigerator until use. Decoctions to be used in the experiment were prepared as 50, 66, 75 and $80 \%$ concentrations. Then, each medium of about $120 \mathrm{ml}$ quantity, prepared from different concentrations, separately was put into $250 \mathrm{ml}$ Erlenmeyer flasks and sterilized by autoclaving at $121^{\circ} \mathrm{C}$ for $15 \mathrm{~min}$.

\subsection{Analysis}

The effect of decoctions at different concentrations $(50,66,75$ and $80 \%)$ was determined against $A$. niger, $A$. parasiticus, A. alternata, B. cinerea, $F$. oxysporum and $P$. digitatum grown on Czapek Dox agar. Potato dextrose medium containing the decoctions in different concentrations was dispensed into petri dishes $(20 \mathrm{ml} /$ dish). Five $\mathrm{mm}$ discs of the test fungi, cut from periphery of 7 day old cultures, were inoculated upside down separately to each assay plate and incubated at $28{ }^{\circ} \mathrm{C}$. The colony diameter was measured and percent mycelial inhibition was calculated (DEANS \& SVOBODA, 1990). Four replicates of each treatment were similarly maintained and averages calculated. Control sets were simultaneously run without using decoctions of plants.

$$
\mathrm{I}=[(\mathrm{C}-\mathrm{T}) / \mathrm{C}] \times 100
$$

I: Inhibition (\%)

C: Colony diameter of mycelium from control petri plate $(\mathrm{mm})$

$\mathrm{T}$ : Colony diameter of mycelium from test petri plate $(\mathrm{mm})$

\section{Results and discussion}

The inhibitory effects of different concentrations of plant decoctions were tested. The results are shown in Tables 1 and 2.

While decoctions of $P r$. uechtritzii were effective against A. alternata, A. parasiticus, $B$. cinerea and $P$. digitatum during incubation, M. myrtifolia was effective also against $P$. digitatum and $B$. cinerea. The decoction at concentration of $80 \%$ of $P$. uechtritzii had the largest effect on mycelial growth of $A$. alternata, A. parasiticus and P. digitatum. However, none of the concentrations of Pr. uechtritzii showed inhibitory effect against $A$. niger. Also, F. oxysporum showed resistance against all concentrations after five days. High concentrations usually showed high inhibitory effect. 
Table 1

Inhibitory effect of M. myrtifolia decoction at different concentrations (\% inhibition)

\begin{tabular}{|c|c|c|c|c|c|c|c|}
\hline $\begin{array}{l}\text { Incubation } \\
\text { days }\end{array}$ & $\begin{array}{c}\text { Concentrations } \\
\%\end{array}$ & A. alternata & A. niger & A. parasiticus & B. cinerea & F. oxysporum & P. digitatum \\
\hline \multirow[t]{4}{*}{3} & 50 & 2 & $-{ }^{\mathrm{a}}$ & - & 4 & - & 43 \\
\hline & 66 & 3 & 29 & - & 5 & - & 48 \\
\hline & 75 & 13 & 29 & - & 6 & - & 57 \\
\hline & 80 & 13 & 33 & - & 28 & - & 65 \\
\hline \multirow[t]{4}{*}{4} & 50 & 5 & - & - & 5 & - & 66 \\
\hline & 66 & 11 & 31 & - & 7 & - & 70 \\
\hline & 75 & 20 & 31 & - & 8 & - & 71 \\
\hline & 80 & 29 & 37 & - & 25 & - & 72 \\
\hline \multirow[t]{4}{*}{5} & 50 & - & - & - & 6 & - & 54 \\
\hline & 66 & 11 & 43 & - & 24 & - & 68 \\
\hline & 75 & 19 & 49 & - & 24 & - & 68 \\
\hline & 80 & 30 & 51 & - & 27 & - & 69 \\
\hline \multirow[t]{4}{*}{6} & 50 & - & - & 30 & 10 & - & 41 \\
\hline & 66 & 13 & - & 33 & 24 & - & 58 \\
\hline & 75 & 21 & - & 35 & 37 & - & 60 \\
\hline & 80 & 36 & - & 54 & 38 & - & 61 \\
\hline \multirow[t]{4}{*}{7} & 50 & - & - & 32 & 32 & - & 37 \\
\hline & 66 & 18 & - & 35 & 35 & - & 47 \\
\hline & 75 & 28 & - & 38 & 42 & - & 49 \\
\hline & 80 & 44 & - & 53 & 51 & - & 50 \\
\hline \multirow[t]{4}{*}{8} & 50 & - & - & 19 & 36 & - & 32 \\
\hline & 66 & - & - & 24 & 36 & - & 41 \\
\hline & 75 & - & - & 31 & 47 & - & 44 \\
\hline & 80 & - & - & 47 & 52 & - & 48 \\
\hline \multirow[t]{4}{*}{9} & 50 & - & - & 9 & 42 & - & 31 \\
\hline & 66 & - & - & 14 & 42 & - & 37 \\
\hline & 75 & - & - & 22 & 50 & - & 41 \\
\hline & 80 & - & - & 41 & 52 & - & 43 \\
\hline \multirow[t]{4}{*}{10} & 50 & - & - & - & 42 & - & 30 \\
\hline & 66 & - & - & - & 44 & - & 33 \\
\hline & 75 & - & - & - & 49 & - & 37 \\
\hline & 80 & - & - & - & 52 & - & 39 \\
\hline
\end{tabular}

${ }^{a}$ No inhibition

None of the concentrations of $M$. myrtifolia showed inhibitory effect against F. oxysporum through incubation. Also, not all concentrations showed inhibitory effect against $A$. parasiticus, $A$. niger and $A$. alternaria during incubation. The most sensitive mould tested against all concentrations of M. myrtifolia were $P$. digitatum and partly $B$. cinerea. However, the concentration of $80 \%$ in accordance with other concentrations of $M$. myrtifolia showed higher inhibitory effect against some mould used in the experiment. $P r$. uechtritzii did not affect the mycelial growth of $A$. niger during incubation at all. 
Consequently, these two decoctions had partly inhibited the growth of some microorganisms used in the experiment. Inhibitory effect of both decoctions was lower than that of the spices themselves and derivatives such as essential oils or oleoresin (AZZOUZ \& Bullerman, 1982; SheleF, 1983; ÖZCAN, 1998). This decrease can be probably due to the evaporation of their essential oils during boiling, because their components have got antimicrobial effect (BEUCHAT, 1976, SHELEF et al., 1980).

Table 2

Inhibitory effect of Pr. uechritzii decoction at different concentrations (\% inhibition)

\begin{tabular}{|c|c|c|c|c|c|c|c|}
\hline $\begin{array}{l}\text { Incubation } \\
\text { days }\end{array}$ & $\begin{array}{c}\text { Concentrations } \\
(\%)\end{array}$ & A. alternata & A. niger & A. parasiticus & B. cinerea & F. oxysporum & P. digitatum \\
\hline \multirow[t]{4}{*}{3} & 50 & 36 & $-{ }^{\mathrm{a}}$ & 4 & 4 & 32 & 24 \\
\hline & 66 & 45 & - & 8 & 6 & 39 & 47 \\
\hline & 75 & 48 & - & 10 & 15 & 55 & 49 \\
\hline & 80 & 48 & - & 12 & 19 & 59 & 57 \\
\hline \multirow[t]{4}{*}{4} & 50 & 38 & - & 6 & 5 & 17 & 50 \\
\hline & 66 & 47 & - & 8 & 7 & 34 & 64 \\
\hline & 75 & 49 & - & 11 & 13 & 41 & 71 \\
\hline & 80 & 51 & - & 14 & 27 & 54 & 71 \\
\hline \multirow[t]{4}{*}{5} & 50 & 37 & - & 10 & 7 & 15 & 52 \\
\hline & 66 & 44 & - & 10 & 12 & 27 & 57 \\
\hline & 75 & 46 & - & 18 & 28 & 36 & 69 \\
\hline & 80 & 57 & - & 29 & 29 & 50 & 71 \\
\hline \multirow[t]{4}{*}{6} & 50 & 31 & - & 23 & 10 & - & 54 \\
\hline & 66 & 34 & - & 32 & 23 & - & 59 \\
\hline & 75 & 44 & - & 39 & 28 & - & 68 \\
\hline & 80 & 57 & - & 61 & 39 & - & 79 \\
\hline \multirow[t]{4}{*}{7} & 50 & 29 & - & 18 & 26 & - & 53 \\
\hline & 66 & 34 & - & 32 & 54 & - & 54 \\
\hline & 75 & 41 & - & 40 & 57 & - & 70 \\
\hline & 80 & 59 & - & 59 & 60 & - & 77 \\
\hline \multirow[t]{4}{*}{8} & 50 & 31 & - & 12 & 31 & - & 52 \\
\hline & 66 & 39 & - & 18 & 58 & - & 56 \\
\hline & 75 & 44 & - & 29 & 60 & - & 65 \\
\hline & 80 & 57 & - & 48 & 62 & - & 75 \\
\hline \multirow[t]{4}{*}{9} & 50 & 36 & - & 11 & 32 & - & 50 \\
\hline & 66 & 42 & - & 14 & 59 & - & 51 \\
\hline & 75 & 45 & - & 25 & 60 & - & 58 \\
\hline & 80 & 47 & - & 39 & 61 & - & 62 \\
\hline \multirow[t]{4}{*}{10} & 50 & 24 & - & 4 & 39 & - & 49 \\
\hline & 66 & 32 & - & 8 & 63 & - & 50 \\
\hline & 75 & 39 & - & 12 & 63 & - & 61 \\
\hline & 80 & 43 & - & 14 & 67 & - & 69 \\
\hline
\end{tabular}

${ }^{a}$ No inhibition 
As a result, the effect of decoctions was not $100 \%$ on mycelial growth, $P r$. uechtritzii showed the highest inhibitory effect against all the moulds tested. While all the concentrations of Pr. uechtritzii showed inhibitory effect against $A$. alternata, $A$. parasiticus, B. cinerea and $P$. digitatum during incubation, M. myrtifolia showed inhibitory effect against only $P$. digitatum and $B$. cinerea. The most sensitive microorganism to both water decoctions was $P$. digitatum. So, the higher decoction concentrations of both plants will probably inhibit the mycelial growth of A. alternaria, B. cinerea and $P$. digitatum.

\section{References}

AZZOUZ, M. A. \& BULlERMAN, L. B. (1982): Comparative antimycotic effects of selected herbs, spices, plant components and commercial antifungal agents. J. Fd Protect., 45, 1298-1301.

BENJILALI, B., TANTAOUI-ElARAKI A., AYADI. A. \& IHLAL, M. (1984): Method to study antimicrobial effects of essential oils: Application to the antifungal activity of six Moroccan essences. J. Fd Protect., 47, $748-752$.

BEUCHAT, L. R. (1976): Sensitivity of Vibrio parahaemolyticus to spices and organic acids. J. Fd Sci., 41, 899-902.

BOYRAZ, N. \& ÖZCAN, M. (1997): Bitki patojeni funguslara bazı yerli baharat ekstrakt ve uçucu yağlarının antifungal etkileri. (Antifungal effects of some Turkish spice extracts and essential oils on plant pathogen fungi.) Gida (Food), 22, 457-462.

DEANS, S. G. \& SVOBODA, K. P. (1990): The antimicrobial properties of marjoram (Origanum majorana L.) volatile oil. Flavour Fragr. J., 5, 187-190.

FARAG, R. S., DAW, Z. Y. \& ABO-RAYA, S. H. (1989): Influence of some spice essential oils on Aspergillus parasiticus growth and production of aflatoxins in a synthetic medium. J. Fd Sci., 54, 74-76.

GRAHAM, H. D. \& GRAHAM, E. J. F. (1987): Inhibition of Aspergillus parasiticus growth and toxin production by garlic. J. Fd Safety, 8, 101-108.

Hitokoto, H., MorozUMI, S., WAUKE, T., SAKAI. S. \& KURATA, H. (1980): Inhibitory effect of spices on growth and toxin production of toxigenic fungi. Appl. environm. Microbiol., 39, 818-822.

ÖZCAN, M. (1998): Inhibitory effects of spice extracts on the growth of Aspergillus parasiticus NRRL 2999 strain. Z. Lebensmittelunters. u. -Forsch. A, 207, 253-255.

SHELEF, L. A., NAGLIK, O. A. \& BOGEN, D. W. (1980): Sensitivity of some common food-borne bacteria to the spices sage, rosemary, and allspice. J. Fd Sci., 45, 1042-1044.

SHELEF, L. A. (1983): Antimicrobial effects of spices. J. Fd Sci., 6, 29-44.

ZAIKA, L. L., KISSINGER, J. C. \& WASSERMAN, A. E. (1983): Inhibition of lactic acid bacteria by herbs. $J . F d$ Sci., 48, 1455-1459. 